\title{
Implementation of Cavity Perturbation Method for Determining Relative Permittivity of Non Magnetic Materials
}

\author{
FAHIM GOHAR AWAN*, NAQUASH AHMED SHEIKH*, SUHAIL AFTAB QURESHI*, AND \\ NOOR MUHAMMAD SHEIKH*
}

RECEIVED ON 27.11.2015 ACCEPTED ON 11.05.2016

\begin{abstract}
Techniques for the cavity measurement of the electrical characteristics of the materials are well established using the approximate method due to its simplicity in material insertion and fabrication. However, the exact method which requires more comprehensive mathematical analysis as well, owing to the practical difficulties for the material insertion, is not mostly used while performing the measurements as compared to approximate method in most of the works. In this work the comparative analysis of both the approximate as well as Exact method is performed and accuracy of the Exact method is established by performing the measurements of non-magnetic material Teflon within the cavity.
\end{abstract}

Key Words: Cavity, Perturbation Method, Exact Method.

\section{INTRODUCTION}

$\mathrm{T}$

he microwave engineering and electromagnetism is established as a mature field since the basic principles of electromagnetics were established nearly a century ago and its widely used application radar is in place from Second World War arena. Despite the older standing in the field of engineering, the innovative development in solid state devices at higher frequencies, radio frequency technology, microwave integrated circuits and the extensive consumer related applications of microwave system makes micorowave engineering a vibrant and active field.

The paper deals with measurement of the relative permittivity of non-magnetic material Teflon using cylindrical cavity resonator by the perturbation techniques. Once established and confirmed with Teflon which is a non-magnetic material, the technique can later be employed for the measurement of the permittivity of other materials. This can subsequently be used for manufacturing of the materials of the desired permittivity $\varepsilon_{\mathrm{r}}$ and hence impedance $\mathrm{Z}\left(\right.$ since $\left.=377 \sqrt{\varepsilon_{\mathrm{r}}}\right)$ for different microwaves application.

In this paper we have simulated the cavity resonator to ascertain the proper mode excitation inside the cavity and later designed the cylindrical cavity in practice and performed the dielectric permittivity measurement for consistency.

The cylindrical cavity resonator acts as an electromagnetic boundary value problem subjected to boundary conditions, whose solution in terms of

* Department of Electrical Engineering, University of Engineering \& Technology, Lahore.

Mehran University Research Journal of Engineering \& Technology, Volume 36, No. 2, April, 2017 [p-ISSN: 0254-7821, e-ISSN: 2413-7219] 
Magnetic and Electric fields are derived from the Maxwell Equations or the Wave Equations. However, there are many field configurations called modes which are solutions of Maxwell Equations. The predominant modes are TEM, TE and TM modes. These modes determine the resonant frequency of the cavity. They can be excited inside the cavity by coupling energy through a magnetic loop (magnetic dipole) or through an electric probe (electric dipole) protruding inside the cavity. The resonant frequency of the cavity is required to determine the dimensions of the cavity to be designed.

Perturbation techniques are applied upon the cavity resonator causing a change in resonant frequency. The change in resonant frequency can be used to determine the permittivity of samples. The cavity is designed for $\mathrm{TM}_{010}$ mode causing the maximum change in the resonant frequency after perturbation and hence accurate measurement of the permittivity [1].

Before fabrication and actual measurements, the design is simulated on Electromagnetic simulation tool HFSS to confirm the proper $\mathrm{TM}_{010}$ mode excitation at the desired frequency with the loop as well as probe excitation. This is verified from the Electric, Magnetic Field and the Current distribution generated by HFSS. Based upon the accuracy of loop excitation, it is then employed for the actual permittivity measurements.

Finally the actual measurements are performed to determine the permittivity of the material by two configurations called the Approximate and Exact Method respectively. The results obtained by the two methods are finally compared and the accuracy of the Exact Method over the Approximate Method, through which most of the measurements subjected to its simplicity in manufacturing and sample insertions, is established.
A variety of techniques are available in literature for material permeability and permittivity measurements [26]. For the measurement of complex permittivity with highQ (Quanlity Filter) [2] describes a planar substrate integrated waveguide cavity resonator technique. Various analytical solutions for small cavity perturbation in a classis form are enlisted in [3]. On careful modification in Q equation for extremely low-loss dielectric samples [6] showed an increased accuracy of resonant perturbation method. Cavity resonators are often modified by making small changes in their shape or by introducing small piece of dielectric or metallic materials [7-12]. For the measurement of complex permittivity of dielectric materials with arbitrary size and shape, [11] presented a simple cavity measurement technique and used Teflon for comparative results. The resonant frequency of a cavity can be easily optimized with a small screw that enters the cavity volume, by changing the size of the cavity with a movable wall or by introducing a sample under test inside resonator so that electromagnetic properties of the sample are deduced from the change in resonant frequency. In this paper we will envisage that the perturbation techniques can be employed to determine the electrical characteristics (permittivity or permeability) of material under test.

\section{DESIGN PROBLEM}

The cylindrical cavity is a section of cylindrical waveguide of length ' $d$ ' and radius ' $a$ ' with the short circuiting plates at the ends as shown in Fig. 1. Both magnetic and electric fields exist inside the cavity and total energy corresponding to these fields is stored in the cavity. The dissipation of this energy is either in the cavity metallic walls or in the dielectric cavity filling as well [13]. Thus the dielectric filling will affect the resonant frequency as well as the quality factor Q of the cavity. When the cavity is tuned to frequency of unknown source, it absorbs the maximum power from the input 
line. Cylindrical cavity resonator is a boundary value problem and Maxwell or the Wave equations can be employed to get electric and magnetic field components in the cylindrical coordinates.

A step by step design procedure is described in [14]. Owing to the field distribution of current $\mathrm{TM}_{0 \mathrm{n} 0}$ cylindrical cavities are widely used and the $\mathrm{TM}_{010}$ mode is most widely used that has the lowest cutoff frequency, also called as the dominant mode. The resonant frequency of this mode is independent upon the resonator length.

$\mathrm{f}_{\mathrm{r}}=\mathrm{f}_{\mathrm{npq}}=\frac{1}{2 \pi \sqrt{\mu \varepsilon}} \sqrt{\left[\frac{\mathrm{x}_{\mathrm{np}}}{\mathrm{a}}\right]^{2}+\left[\frac{\mathrm{q} \pi}{\mathrm{d}}\right]^{2}}$

Here $\mathrm{q}$ is the number of half cycle variations in the direction of propagation, $a$ is the cavity radius and $d$ is the cavity length where $x_{n p}$ is the zeroth of Bessel Function. Equation (1) is used to design the cavity resonator of the desired frequency for any TM mode. The maximum change in the electric field will take place when the sample is inserted in the cavity centre so would be the resonant frequency of the cavity on inserting with the sample [15$16]$.

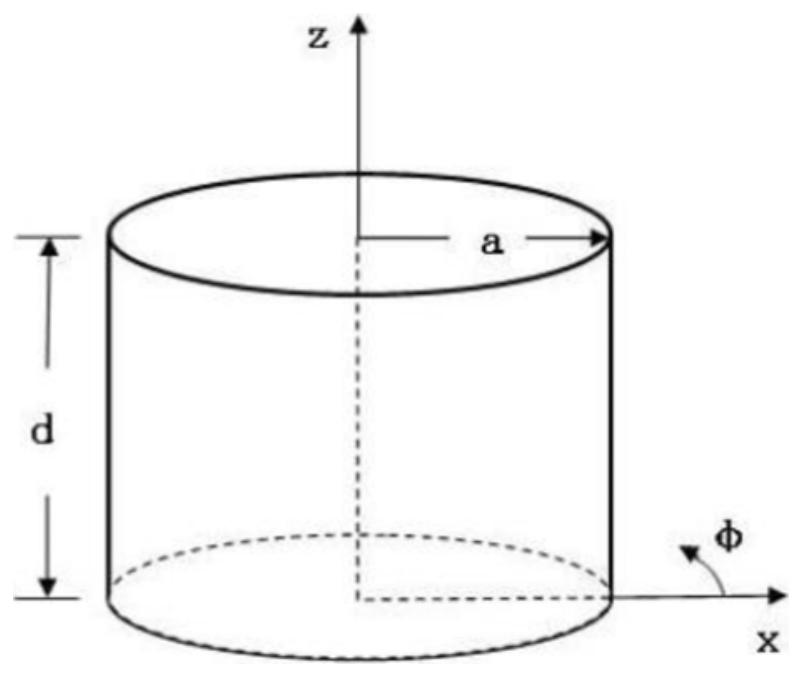

FIG. 1. CYLINDRICAL CAVITY RESONATOR

\section{SIMULATIONS AND ANALYSIS ON HFSS}

$\mathrm{TM}_{010}$ mode excitation was chosen for the design purpose as the field pattern suggests that the maximum change in resonant frequency will take place after the sample insertion, thus enabling accurate measurement of the electrical characteristics of the inserted sample [17-18]. The mode can be excited in the cavity using a metallic loop. Simulations on HFSS are performed to confirm the proper mode excitation at the desired frequency.

The cylindrical cavity excited for $\mathrm{TM}_{010}$ mode through the loop coupling is shown in Fig. 2. The resonant frequency of the TM mode is given by Equation (1). For $\mathrm{TM}_{010}$ mode, $\mathrm{n}=0 ; \mathrm{p}=1 ; \mathrm{q}=0$. Also from Bessel chart given in Table $1 \mathrm{x}_{\mathrm{np}}=2.405$. By substituting the values for the designed frequency, $\mathrm{f}_{\mathrm{npq}}=1 \mathrm{Ghz}, \mathrm{a}=115 \mathrm{~cm}$. In order to achieve the maximum $\mathrm{Q}, \mathrm{d}=2 \mathrm{a}=230 \mathrm{~cm}$.

The cavity is showing the resonance at $1.012 \mathrm{GHz}$ in Fig. 3. The field patterns in Fig. 4(a) suggest that $\mathrm{TM}_{010}$ is properly excited. Electric field is maximum at the centre and minimum at the cylindrical boundary. Similarly magnetic field is minimum at the centre and maximum at the boundary.

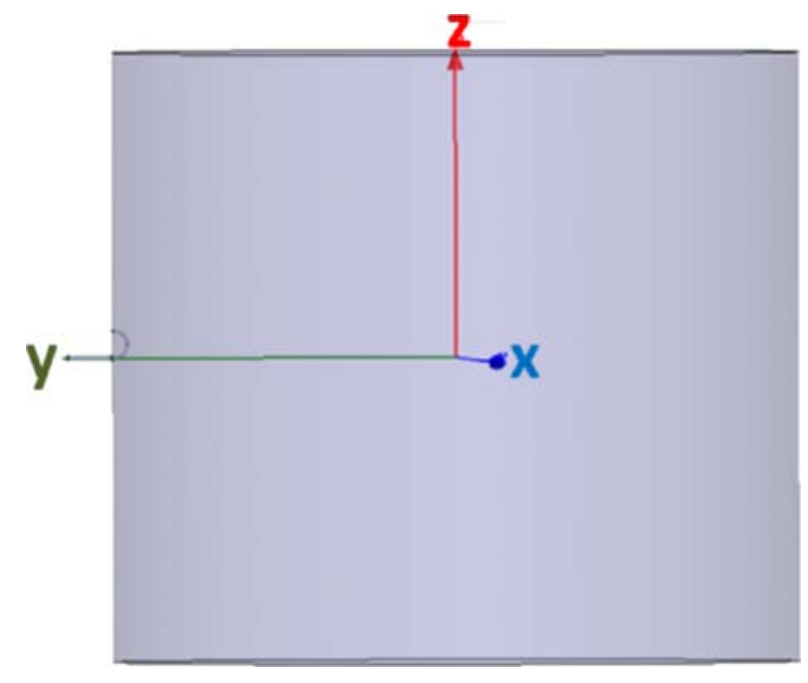

FIG. 2. LOOP COUPLED CYLINDRICAL CAVITY

Mehran University Research Journal of Engineering \& Technology, Volume 36, No. 2, April, 2017 [p-ISSN: 0254-7821, e-ISSN: 2413-7219] 
The current consists of the conduction current along the conducting surface and displacement current between the upper and the lower walls as shown in Fig. 4(b). With all these simulations (Figs. 2-4), it is confirmed that $\mathrm{TM}_{010}$ mode is properly excited in the empty cavity and resonant nearly at the desired frequency.
The loop-coupled cavity is perturbed with Teflon which is placed at the centre of the bottom conducting plate [19-20]. The electric field is maximum at this location to ensure the maximum change in the resonant frequency. The sample size inserted is comparable to the cavity size to ensure the accuracy of the method as shown in Fig. 5.

TABLE 1. ROOTS FOR TM MODES

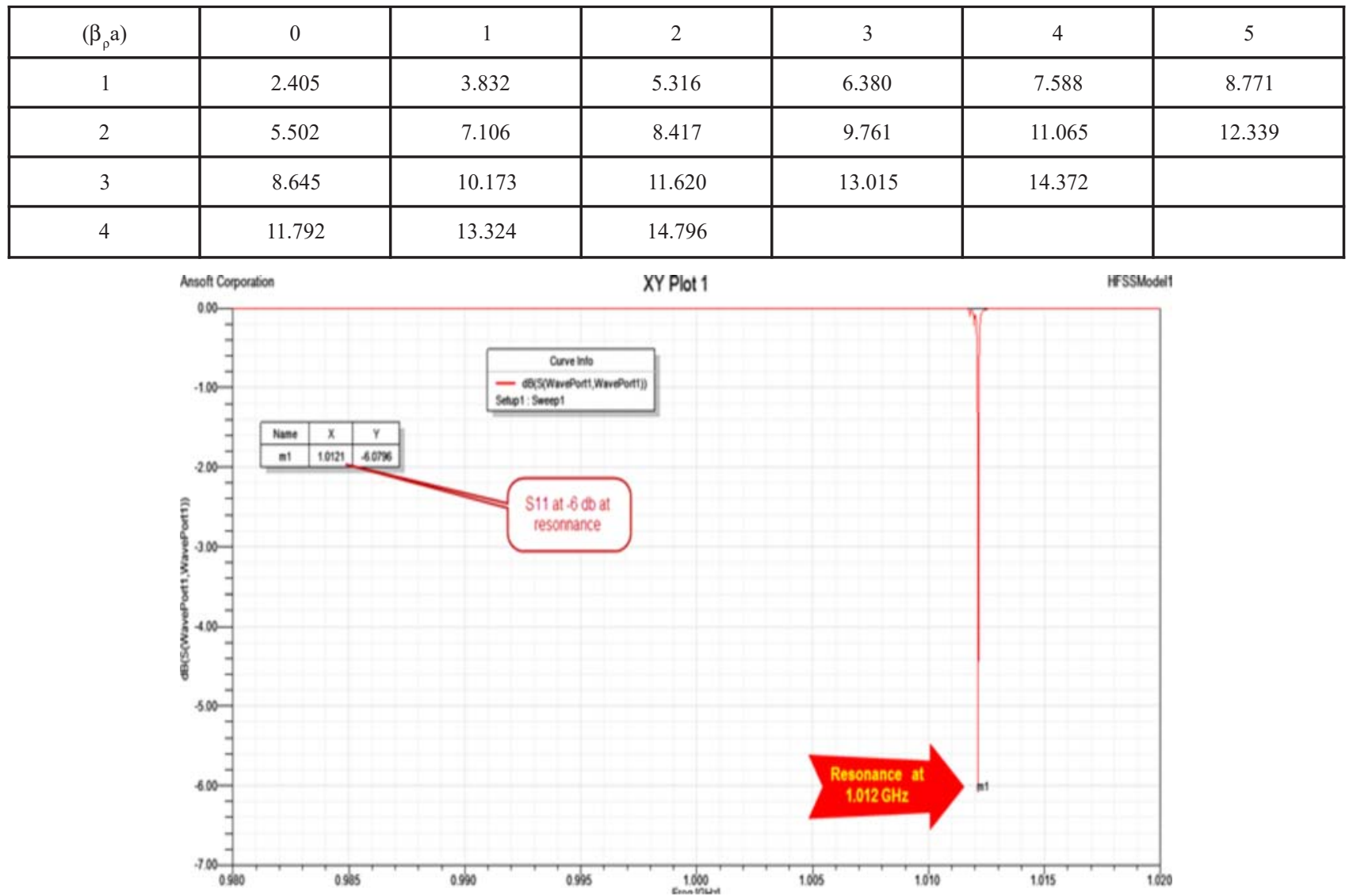

FIG. 3. $S_{11}$ LOOP COUPLED CYLINDRICAL CAVITY

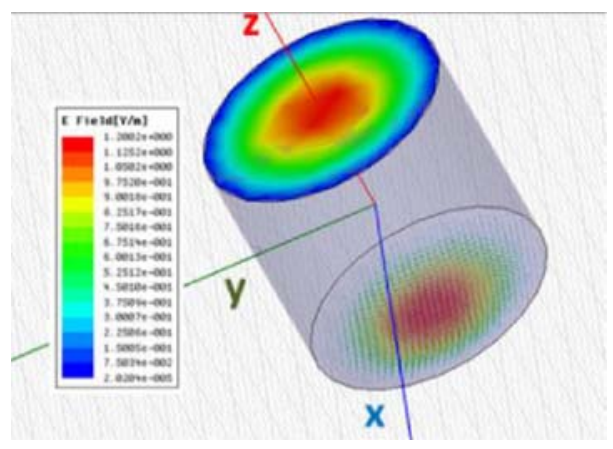

(a) ELECTRIC FIELD

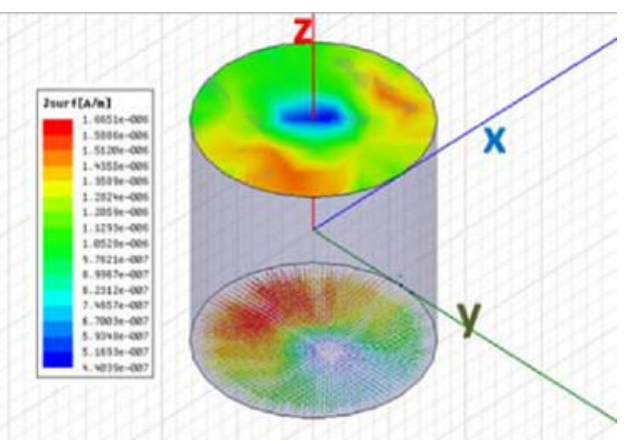

(b) CURRENT DISTRIBUTION

FIG. 4. CURRENT AND FIELD DISTRIBUTION OF LOOP COUPLED CYLINDRICAL CAVITY 
The resonant frequency of the cavity is changed after the sample placement to $0.9817 \mathrm{GHz}$. Additional unwanted mode is also excited at nearly $1.011 \mathrm{GHz}$ as shown in Fig. 6.

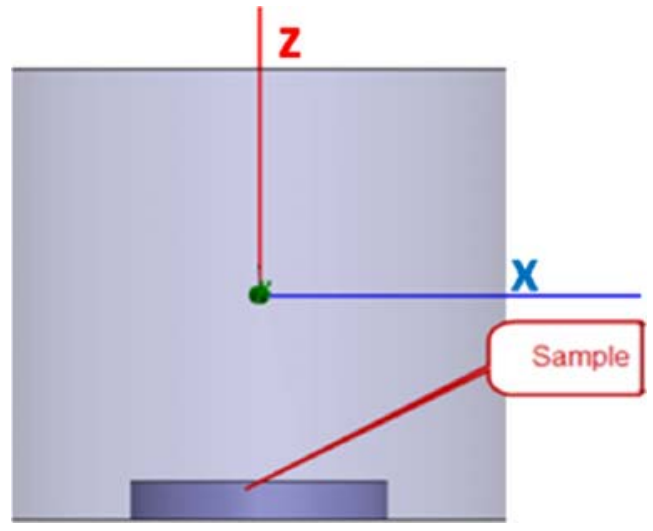

FIG. 5. LOOP COUPLED CYLINDRICAL CAVITY PERTURBED WITH TEFLON
The strength of the electric and magnetic field has increased due to the sample introduction. The electric field is still maximum at the centre and minimum at the boundary as per the boundary conditions as shown in Fig. 7(a).

The magnetic field has also increased at the boundary after the sample positioning and is minimum at the centre as shown in Fig. 7(b).

The surface current density will converge on the top surface and diverge at the bottom surface owing the direction of the magnetic as shown in Fig. 7(c).

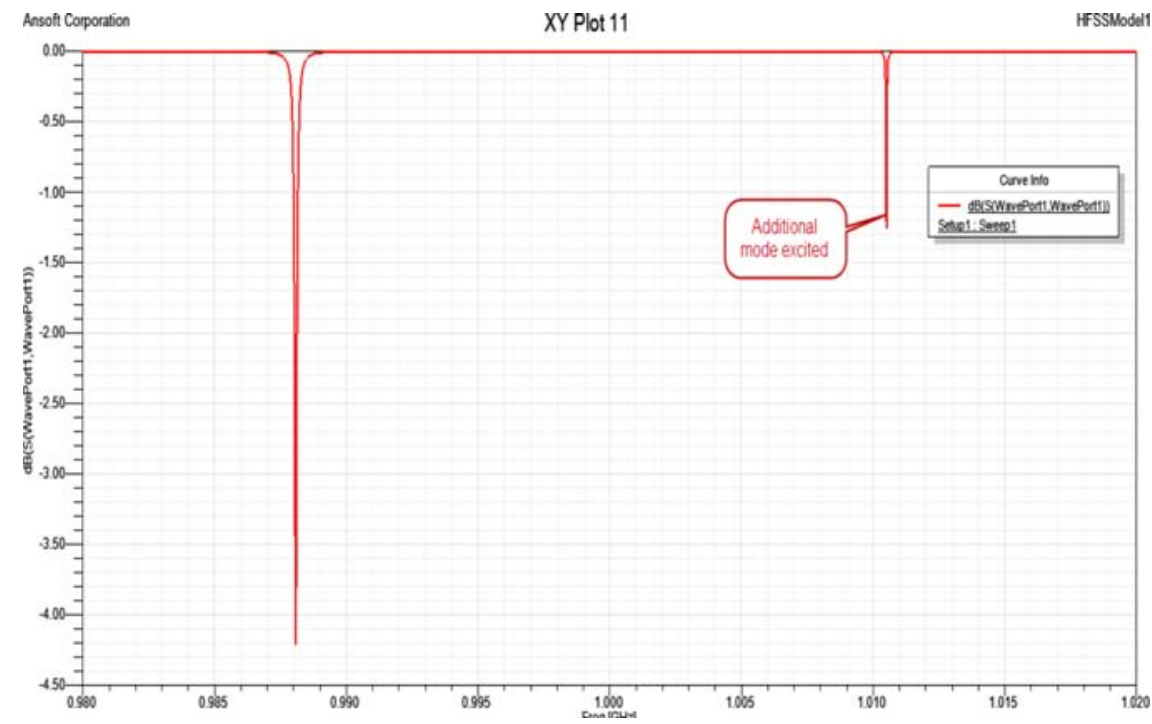

FIG. 6. $S_{11}$ LOOP COUPLED CYLINDRICAL CAVITY PERTURBED WITH TEFLON

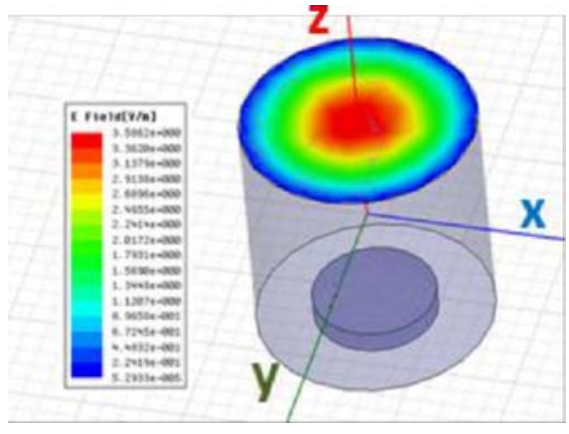

(a)Electric Field

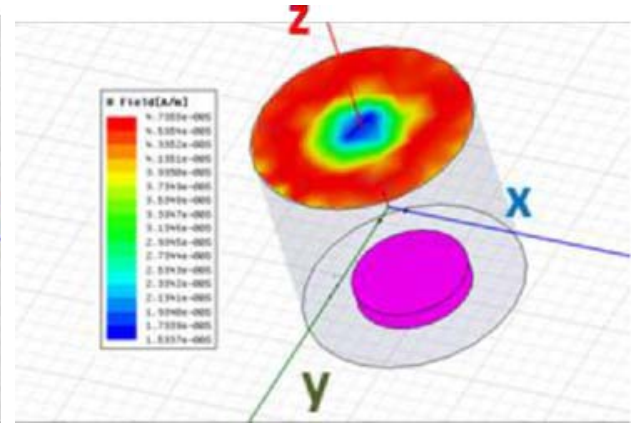

(b) Magnetic Field

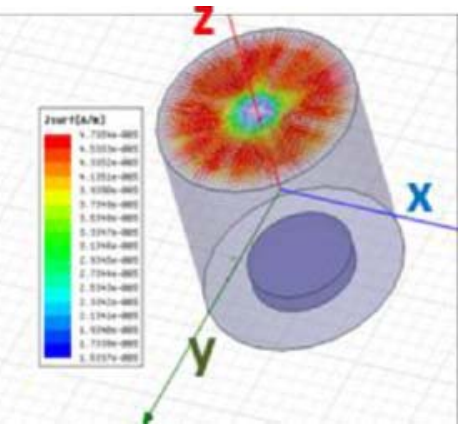

(C) Current Distribution

FIG. 7. CURRENT AND FIELD DISTRIBUTION OF LOOP COUPLED CYLINDRICAL CAVITY PERTURBED WITH TEFLON

Mehran University Research Journal of Engineering \& Technology, Volume 36, No. 2, April, 2017 [p-ISSN: 0254-7821, e-ISSN: 2413-7219] 
The approximation for the change in the resonant frequency after the perturbation is calculated for $\varepsilon_{\mathrm{r}}=1.77$ while actual $\varepsilon_{\mathrm{r}}=2.55$ with $\%$ age error $13 \%$, which shows that the method employed for the simulation purpose gives the permittivity with acceptable error and can be used for the actual permittivity calculations. Owing to less error due to loop coupling in the simulation results, it is employed for the actual permittivity measurements.

\section{PHYSICAL IMPLEMENTATION AND ACTUAL MEASUREMENTS}

The cavity obtained has the following dimensions $\mathrm{a}=107.75 \mathrm{~mm}$, which using Equation $(1)$ gives $\mathrm{f}_{010}=1.067285$ GHz. The HFSS Model which is used for actual cavity resonator is shown in Fig. 8. The test bed and the Measurement Setup in the lab are shown in Fig. 9. The observations are recorded with an Agilent Network Analyzer.

The cylindrical cavity resonator of the desired dimension is designed and excited through the $\mathrm{M}_{010}$. The sample under test is placed exactly at the centre of the cavity.
The response of the cavity is measured through the network analyzer and resonant frequency observed is $1.0629 \mathrm{GHz}$ as shown in Fig. 10(a). After perturbation with the Teflon, the new resonant frequency is measured on the network analyzer and is recorded to be $1.03732 \mathrm{GHz}$ as shown in Fig. 10(b).

The actual and the measured resonant frequency are given as $\omega=1.03732 \mathrm{GHz}$ while $\omega_{0}=1.0629 \mathrm{GHz}$. And

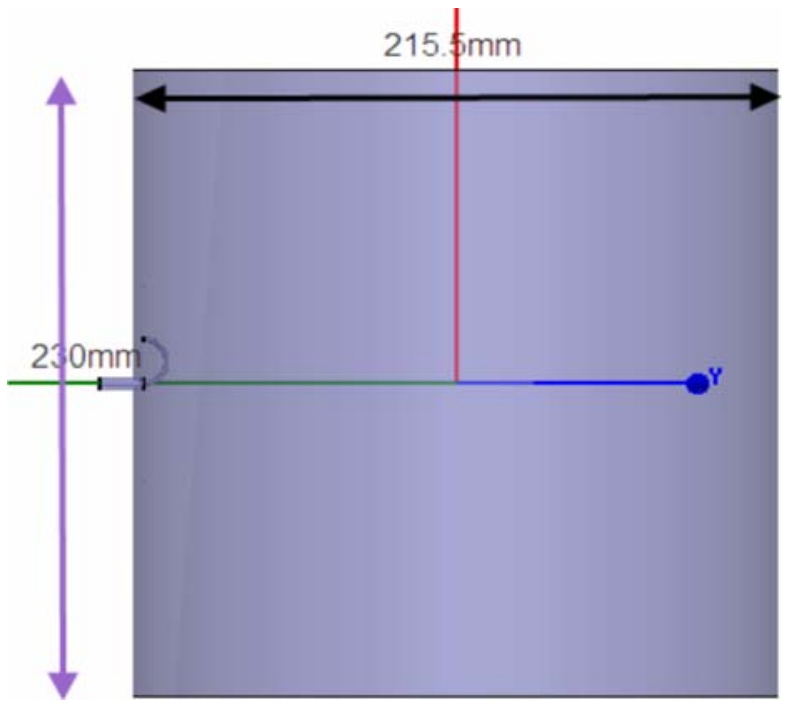

FIG. 8. HFSS MODEL OF ACTUAL CAVITY RESONATOR NETWORK ANALYZER MEASUREMENT SETUP

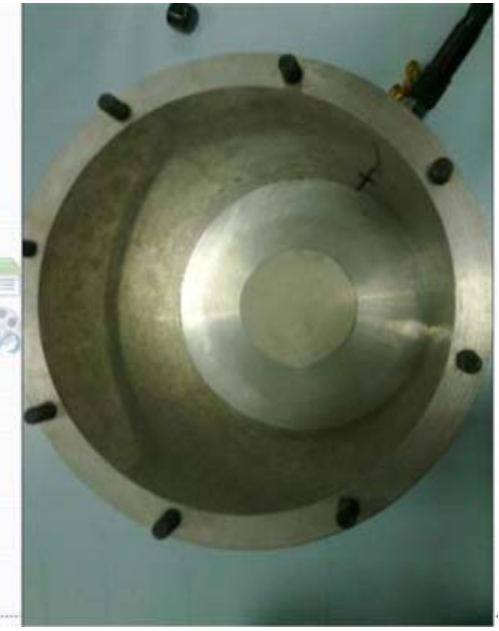

FIG. 9. NETWORK ANALYZER MEASUREMENT SETUP 
the change in the resonant frequency after perturbation is given as $\frac{\omega-\omega_{0}}{\omega}$ [21], which evaluates permittivity to be $\varepsilon_{\mathrm{r}}=1.66$, while $\varepsilon_{\mathrm{r}}=2.05$, leading to a $20 \%$ error.

The error contributed by this approximate method is beyond the acceptable limit and cannot be employed for the actual permittivity calculations. For the method to be accurate the sample should be placed exactly at the centre. The error can be reduced by increasing the volume of the sample or by reducing the volume of the cavity. In order to improve the measurement accuracy, measurement is done using the Exact Method which ensures the accurate placement of the sample in the centre.

In order to further investigate the problem for the permittivity calculation additional method called the exact method is employed in which concentric rod of material under test of the same height as that of cavity is inserted in the cavity instead of sample placed at the bottom of the cavity as in the previous case. The rod radius is $\mathrm{c}$ and height. This method will give the exact frequency of resonance as shown in Fig. 11.

The solution to the boundary value problem is provided in Time Harmonic Electromagnetic Fields by Harrington.

$$
\frac{1}{\eta} \frac{\mathrm{J}_{\mathrm{o}}^{\prime}(\beta \mathrm{c})}{\mathrm{J}_{\mathrm{o}}(\beta \mathrm{c})}=\frac{1}{\eta_{\mathrm{o}}}\left[\frac{\mathrm{N}_{\mathrm{o}}(\beta \mathrm{a}) \mathrm{J}_{\mathrm{o}}^{\prime}(\beta \mathrm{c})-\mathrm{N}_{\mathrm{o}}^{\prime}(\beta \mathrm{a}) \mathrm{J}_{\mathrm{o}}(\beta \mathrm{c})}{\mathrm{N}_{\mathrm{o}}(\beta \mathrm{a}) \mathrm{J}_{\mathrm{o}}(\beta \mathrm{c})-\mathrm{N}_{\mathrm{o}}(\beta \mathrm{a}) \mathrm{J}_{\mathrm{o}}(\beta \mathrm{c})}\right]
$$

Where $\mathrm{J}_{\mathrm{o}}$ is Bessel Function of First Kind and $\mathrm{N}_{\mathrm{o}}$ is Bessel Function of Second Kind. The Teflon sample inserted has radius $\mathrm{c}=6.25 \mathrm{~cm}$ while the cavity radius is given as $\mathrm{a}=107.75 \mathrm{~mm} . \beta$ is the propagation constant.. Solving in Equation (2) on Matlab gives the exact resonant frequency to be $1.058 \mathrm{GHz}$ as shown in Fig. 12.

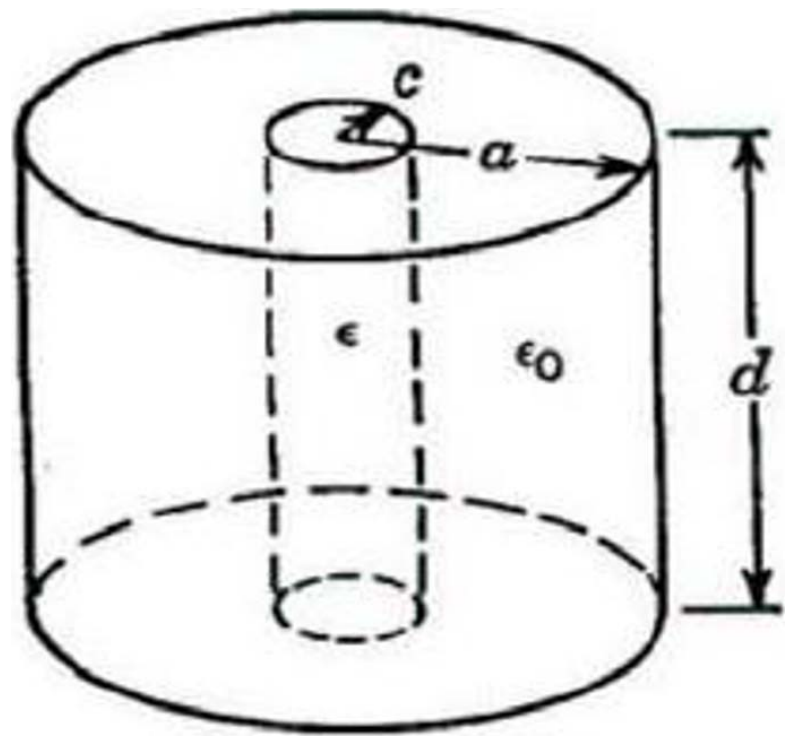

FIG. 11. EXACT METHOD FOR PERMITTIVITY MEASUREMENT

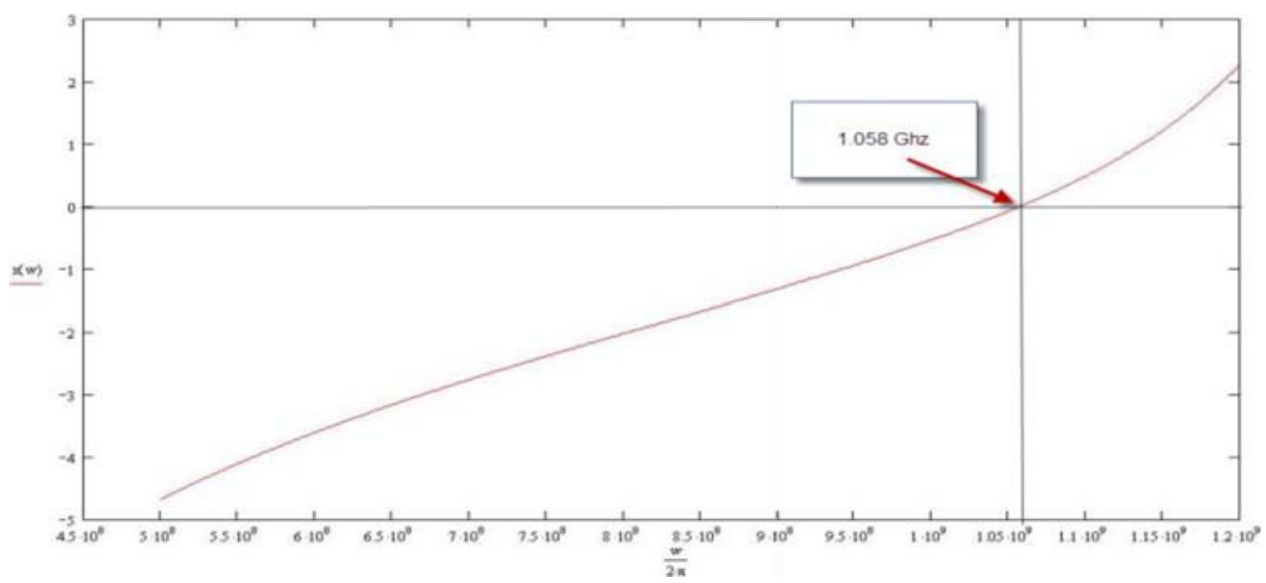

FIG. 12. RESONANT FREQUENCY OF EXACT METHOD

Mehran University Research Journal of Engineering \& Technology, Volume 36, No. 2, April, 2017 [p-ISSN: 0254-7821, e-ISSN: 2413-7219] 
Since the excitation mode is $\mathrm{TM}_{010}$, the resonant frequency which is independent upon the cavity length, the cavity is cut into half so the sample can be properly placed in the centre along its length as shown in Fig. 13. The resonant frequency is independent upon the cavity length and measured to be $1.0621 \mathrm{GHz}$ as shown in Fig. 14.

The response of the cavity after the perturbation by placing the sample along the entire length of the cavity is $\omega=1.055 \mathrm{GHz}$. Here $\omega=1.055010246 \mathrm{GHz}$ and $\omega_{0}=$ $1.062125329 \mathrm{GHz}$, which evaluates $\varepsilon_{\mathrm{r}}=2.23$, while actual $\varepsilon_{\mathrm{r}}$ $=2.05$, with $9 \%$ error. The error contributed by the exact method is substantially less than Approximate Method. All the above results are summarized in Table 2.

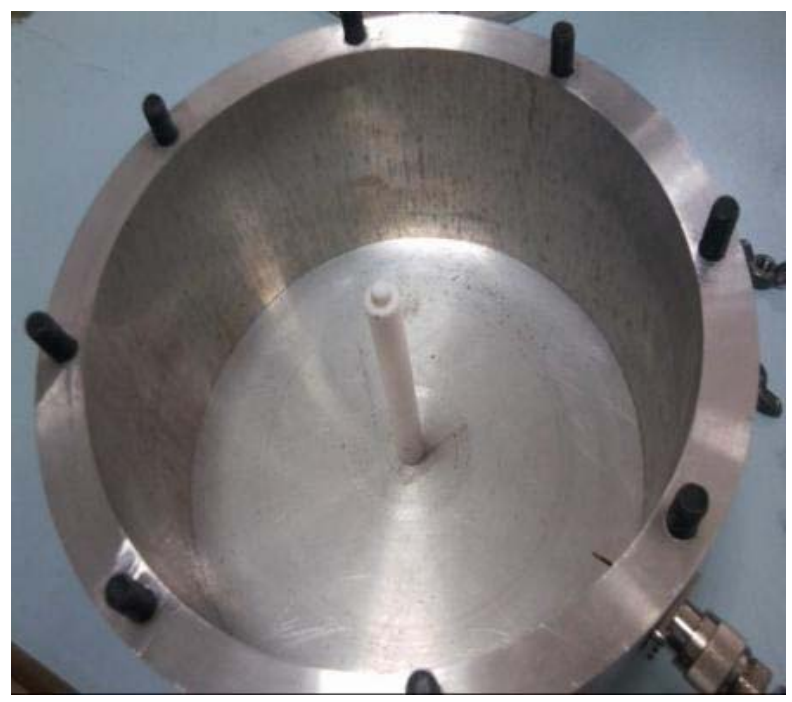

FIG. 13. ACTUAL CAVITY USED IN EXACT METHOD

\section{CONCLUSION}

The cavity perturbation method was employed to determine the relative permittivity of non-magnetic material (Teflon). Simulations were performed to confirm the proper mode excitation and later physical cavity was designed to measure the actual response and the actual permittivity. However the percentage error found using the method was beyond the acceptable limits, so Exact Method was employed in the actual measurements and recalculation were done for the permittivity. There was a substantial improvement in the permittivity. Thus this method described can be established as accurate and more precise for the unknown permittivity measurements of the materials.

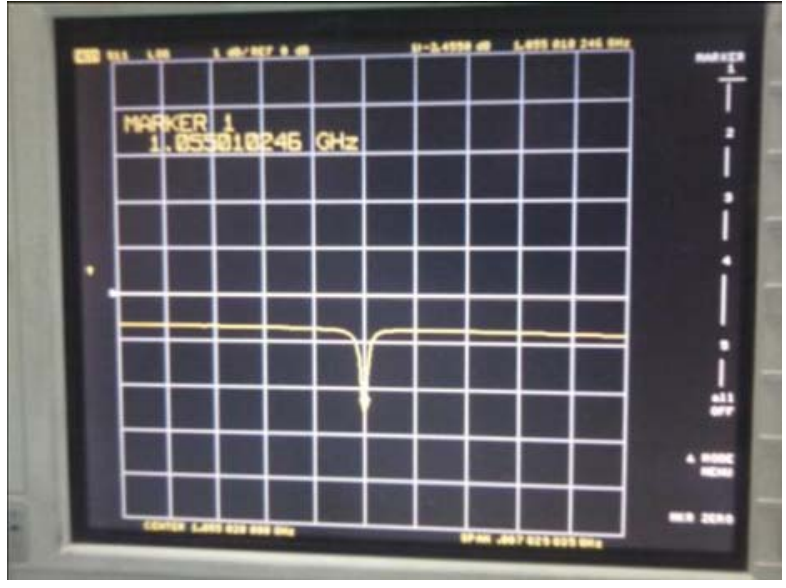

FIG. 14. NETWORK ANALYZER MEASUREMENT OF RESONANT FREQUENCY FOR PERTURBED CAVITY WITH EXACT METHOD

TABLE 2. PERMITTIVITY CALCULATION FOR APPROXIMATELY METHOD AND EXACT METHOD

\begin{tabular}{|c|c|c|c|c|c|}
\hline $\begin{array}{c}\text { Method } \\
\text { (Loop Coupled Cavity) }\end{array}$ & $\begin{array}{c}\text { Measured Resonant } \\
\text { Frequency of } \\
\text { Unperturbed Cavity } \\
(\mathrm{GHz})\end{array}$ & $\begin{array}{c}\text { Measured Resonant } \\
\text { Frequency of } \\
\text { Perturbed Cavity } \\
(\mathrm{GHz})\end{array}$ & $\begin{array}{c}\text { Measured } \\
\text { Permittivity }\end{array}$ & $\begin{array}{c}\text { Actual } \\
\text { Permittivity }\end{array}$ & $\begin{array}{c}\text { Percentage Error } \\
(\%)\end{array}$ \\
\hline Approximate & 1.0629 & 1.03732 & 1.66 & 2.05 & 20 \\
\hline Exact & 1.0621 & 1.055 & 2.24 & 9 \\
\hline
\end{tabular}

Mehran University Research Journal of Engineering \& Technology, Volume 36, No. 2, April, 2017 [p-ISSN: 0254-7821, e-ISSN: 2413-7219] 


\section{ACKNOWLEDGEMENT}

The authors graciously thank personnel in Wireless and DSP Lab. University of Engineering \& Technology, Lahore, Pakistan, for their constructive suggestions.

\section{REFERENCES}

Abdulnabi, R.A., "The Cavity Perturbation Method for the Measurement of the Dielectric Properties of (Polystyrene/Carbon Black) Composite", Journal of Basrah Researches (Sciences), Volume 37, No. 1, pp.1-7, 2011.

[2] Saeed, K., Pollard, R.D., and Hunter, I.C., "Substrate Integrated Waveguide Cavity Resonators for Complex Permittivity Characterization of Materials", IEEE Transactions on Microwave Theory and Techniques, Volume 56, No. 10, pp. 2340-2347, October, 2008.

[3] Brodwin, M.E., and Parsons, M.K., "New Approach to the Perturbation of Cavity Resonators by Homogeneous, Isotropic Spheres", Journal of Applied Physics, Volume 36, pp. 494-504, 1965.

[4] Yu, K.B., Ogourtsov, S.G., Belenky, V.G., Maslenikov, A.B., and Omar, A.S., "Accurate Microwave Resonant Method for Complex Permittivity Measurements of Liquids [Biological]", IEEE Transactions on Microwave Theory and Techniques, Volume 48, No. 11, pp. 2159-2164, November, 2000.

Mathew, K.T., and Raveendranath, U., "Cavity Perturbation Techniques for Measuring Dielectric Parameters of Water and other Allied Liquids", Sensors Update, Volume 7, No. 1, pp. 185-210, Weinheim, Federation Republic of Germany, 2000.

[6] Chen, L., Ong, C.K., and Tan, B.T.G., "Amendment of Cavity Perturbation Method for Permittivity Measurement of Extremely Low-Loss Dielectrics", IEEE Transactions on Instrumentation and Measurement, Volume 48, No. 6, pp. 1031-1037, December, 1999.

[7] Rzepecka, M.A., and Hamid, M.A.K., "Modified Perturbation Method for Permittivity Measurements at Microwave Frequencies", Journal of Microwave Power, Volume 9, No. 4, pp. 317-328, 1974.
Akyel, C., Bosisio, R.G., and April, G.E., "An Active Frequency Technique for Precise Measurements on Dynamic Microwave Cavity Perturbations", IEEE Transactions on Instrumentation and Measurement, Volume 27, No. 4, pp. 364-368, December, 1978.

[9] Akyel, C., and Bosisio, R.G., "New Developments on Automated-Active Circuits for Permittivity Measurements at Microwave Frequencies", IEEE Transactions on Instrumentation and Measurement, Volume 38, No. 2, pp. 496-504, April, 1989.

[10] Sheen, J., "Study of Microwave Dielectric Properties Measurements by Various Resonance Techniques", Measurement, Volume 37, No. 2, pp. 123-130, 2005.

[11] Santra, M., and Limaye, K.U., "Estimation of Complex Permittivity of Arbitrary Shape and Size Dielectric Samples Using Cavity Measurement Technique at Microwave Frequencies", IEEE Transactions on Microwave Theory and Techniques, Volume 53, No. 2, pp. 718-722, February, 2005.

[12] Wu, Y.Q., Tang, Z.X., Xu, Y.H., He, X., and Zhang, B., "Permittivity Measurement of Ferroelectric Thin Film Based on CPW Transmission Line", Journal of Electromagnetic Waves and Applications, Volume 22, No. 4, pp. 555-562, 2008.

[13] Li, X., and Jiang, Y., "Design of a Cylindrical Cavity Resonator for Measurements of Electrical Properties of Dielectric Materials", Master Thesis, 2010.

[14] Ahmed, N., "Simulation and Analysis of Cavity Perturbation Method for Determining Relative Permittivity of Non Magnetic Materials at HFSS", Master Thesis, 2014 (Available online www.uet.edu.pk).

[15] Chang, C.W., Chen, K.M., and Qian, J., "Nondestructive Determination of Electromagnetic Parameters of Dielectric Materials at X-Band Frequencies using a Waveguide Probe System", IEEE Transactions on Instrumentation and Measurement, Volume 46, No. 5, pp. 1084-1092, October, 1997.

[16] Decreton, M.C., and Ramachandraiah, M.S., "Nondestructive Measurement of Complex Permittivity for Dielectric Slabs (Short Papers)", IEEE Transactions on Microwave Theory and Techniques, Volume 23, No. 12, pp. 1077-1080, December, 1975. 
[17] Afsar, M.N., Chamberlain, J., and Chantry, G.W., "HighPrecision Dielectric Measurements on Liquids and Solids at Millimeter and Submillimeter Wavelengths", IEEE Transactions on Instrumentation and Measurement, Volume IM-25, No. 4, pp. 290-294, December, 1976.

[18] Sheen, J., "Measurements of Microwave Dielectric Properties by an Amended Cavity Perturbation Technique", Measurement, Volume 42, No. 1, pp. 57-61, 2009.
Toman, M.P., and Ishii, T.K., "Equivalent-Circuit Parameters of a Cylindrical-Cavity Resonator", Electronics Letters, Volume 3, No. 1, pp. 36-38, January, 1967.

[20] Waldron, R.A., "Perturbation Theory of Resonant Cavities", IEE Proceedings of Monographs Part-C, Volume 107, No. 12, pp. 272-274, September, 1960.

[21] Collin, R.E., "Field Theory of Guided Waves", IEEE Press, Willy, 1991. 